\section{A CHAPTER IN THE HISTORY OF SPECTRUM ANALYSIS.}

WHEN I began to endeavour to apply the principles of spectrum analysis to the investigation of the nature of the heavenly bodies in 1865 , the then idea, based upon Kirchhoff and Bunsen's work of 1859, was

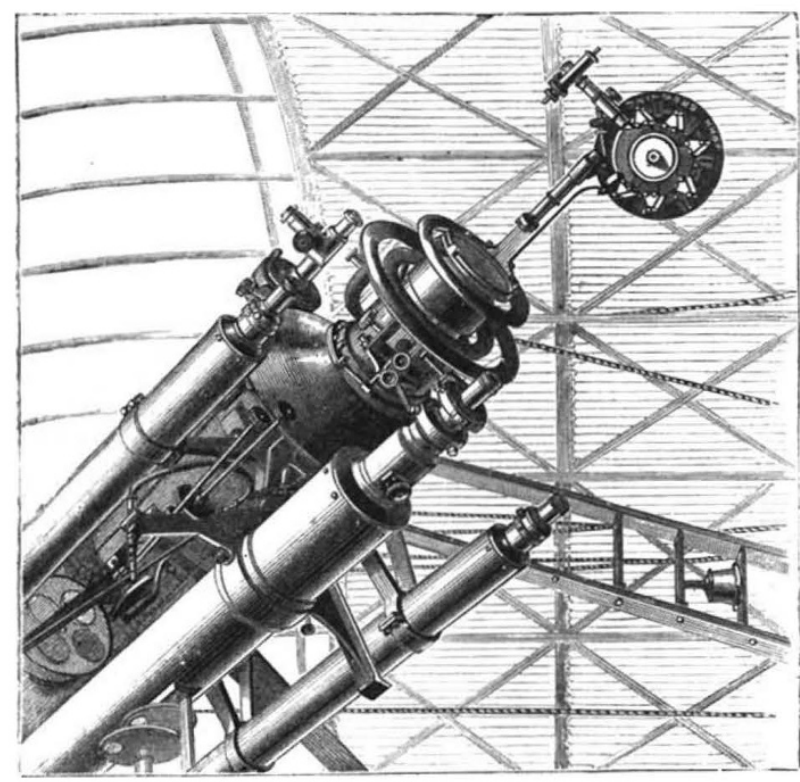

FIG. . - Spectroscope attached to a large refractor which throws an image of the sun on the slit plate.

that the spectrum of a chemical element was one and indivisible-that it could not be changed by temperature or by anything else.

Looking back it is easy to see now that this idea largely depended upon the fact that in the early days low flame temperatures were generally employed, and that it so happens that the substances best visible in the flame, and which were therefore chosen to experiment upon, such as sodium, calcium, potassium, and the like, give us line spectra at low stages of heat.

Hence the first spectroscopic ideas entirely agreed with those of the chemist, that the chemical "atom," defined by a certain "atomic" weight was a manufactured article, indivisible, indestructible. Chemical elementary substances were either composed of these atoms, these indivisible units, or of "molecules" consisting of one or two of them, hence the terms "monatomic" and "diatomic" molecule.

The difference between the spectra of the same element in the solid and gaseous states, in which we have first a continuous and secondly a line spectrum, was ascribed to the restricted motion of the atom in the solid and its freedom in the gaseous state-it was a question of "free path." The difference between the states which gave us the continuous and discontinuous NO. I 536 , vOL. 59] spectra was a physical difference having nothing to do with chemistry. According to the kinetic theory of gases, the particles of all bodies are in a state of continual agitation, and the difference between the solid, liquid and gaseous states of matter is that in a solid body the molecule never gets beyond a certain distance from its initial position. The path it describes is often within a very small region of space. Prof. Clifford, in a lecture upon atoms, many years ago illustrated this very clearly. He supposed a body in the middle of a room held by elastic bands to the ceiling and the floor, and in the same manner to each side of the room. Now pull the body from its place; it will vibrate, but always about a mean position; it will not travel bodily out of its place ; it will always go back again.

We next come to fluids. Concerning these we read "In fluids, on the other hand, there is no such restriction to the excursions of a molecule. It is true that the molecule generally can travel but a very small distance before its path is disturbed by an encounter with some other molecule ; but after this encounter, there is nothing which determines the molecule rather to return towards the place from whence it came than to push its way into new regions. Hence in fluids the path of a molecule is not confined within a limited region, as in the case of solids, but may penetrate to any part of the space occupied by the fluid.

Now we have the motion of the molecule in the solid and the fluid. How about the movement in a gas? "A gaseous body is supposed to consist of a large number of molecules moving very rapidly." For instance, the molecules of air travel about twenty miles in a minute.

"During the greater part of their course these molecules are not acted upon by any sensible force, and therefore move in straight lines with uniform velocity. When two molecules come within a certain distance of each other, a mutual action takes place between them which may be compared to the collision of two billiard balls. Each molecule has its course changed, and starts in a new path.

The collision between two molecules is defined as an "encounter"; the course of a molecule between en counters a "free path." "In ordinary gases the free motion of a molecule takes up much more time than is occupied by an encounter. As the density of the gas increases the free path diminishes."

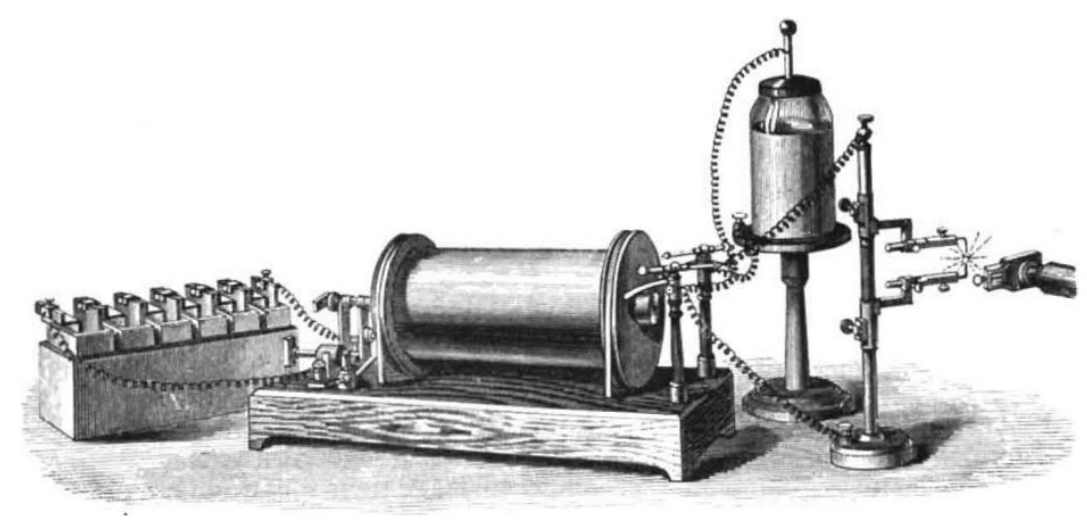

FIG, 2.-The first method of work with the slit of the spectroscope close to the light source. In the experiment illustrated the light source is an electric spark produced by an induction coil with Leyden jar in circuit. The slit end of the collimator is shown to the right.

It will be seen at once that on the view first held that the difference between continuous and discontinuous spectra depended simply upon the solid and gaseous states, no solid could give us a line spectrum ; and the well-known absorption spectra of didymium glass and other solid bodies would be impossible. 
Another important series of facts was soon brought to the front. Plücker and Hittorf in the year 1865 announced that "there is a certain number of elementary substances which when differently treated furnish two kinds of spectra of quite a different character, not having any line or band in common." The difference in character to which reference is here made consists in the spectrum produced at the lower temperature being composed of flutings, which are replaced by lines when the higher temperature is reached.

This was the first blow aimed at the general view-one element one spectrum - to which I have referred above. It was met in two ways.

Taking the line spectrum as representing the true vibration as the chemical unit, I have already shown that the continuous spectrum was explained as due to its physical environment, the solid or liquid state. This, then, had not to be considered from the chemical point of view.

The fluted spectra were boldly ascribed to "impurities," but not always wisely, for, to get rid of the difficulty presented by the two spectra of hydrogen, two perfectly distinct spectra were ascribed to acetylene. Again the "bell-hypothesis" was suggested, according

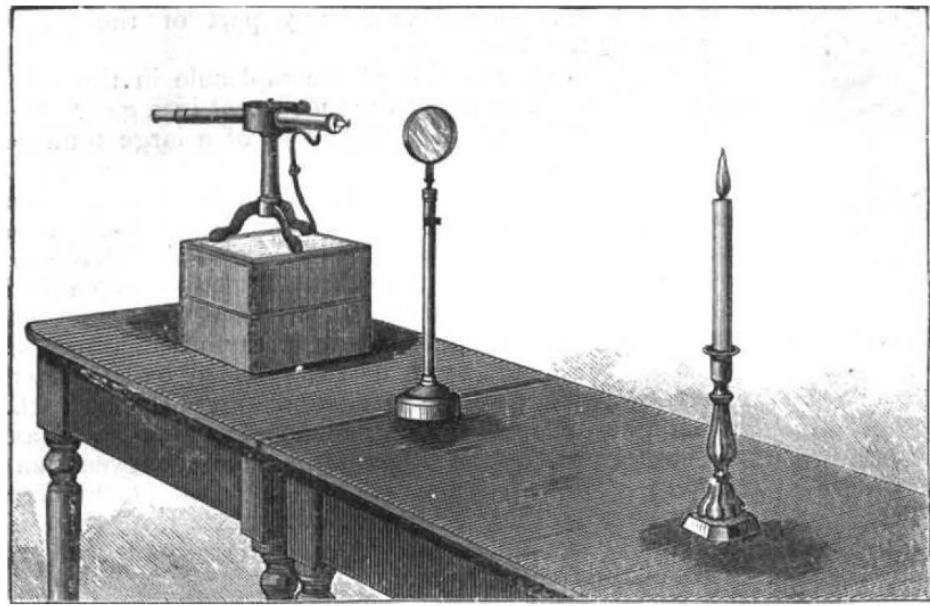

FIG. 3.-The method of throwing an image of the light source (in this case a candle flame) on the slit plate of a laboratory spectroscope.

to which the spectrum did not depend so much upon the substance as upon the way it was made to vibrate. According to this view the same chemical "atom" might have a dozen spectra if struck in a dozen different ways.

But it was answered that this argument proved too much; and for this reason. Mitscherlich showed in I 864 that some bodies known to be chemical compounds when raised to incandescence, give us a spectrum special to the compound ; that is, they have a spectrum of their own; no lines of either of the constituents are seen.

I showed later that when the temperature was sufficient to produce decomposition the lines of the elementary bodies, of which the compound was composed, made their appearances according to the temperature employed. And I also showed that precisely the same thing happens with regard to the fluted and line spectra of the same chemical element. We may get the first alone at a low temperature. We may increase the temperature and dim it slightly, some lines making their appearance; and next, by employing a very high temperature, we can abolish the fluted spectrum altogether and obtain one with lines only.

Since then the difference between the two spectra of NO. I 536 , VOL. 59] the same element was no more marked than the difference between the spectrum of a known compound and its constituents after the compound had been broken up by heat; it was as logical to deny the existence of compound bodies as to deny that more molecular complexities than one were involved in spectral phenomena.

Attacks like these finally caused the chemists to reconsider their position, and some time later, being under the impression, which has turned out to have no justification, that "monatomic" elements like mercury have not fluted spectra, they conceded that the fluted spectra might represent the vibration of the "diatomic" molecule in the "diatomic" elements. This, of course, was to give up the "bell-hypothesis."

At the time when the differences of opinion arising from the existence of fluted as well as line spectra in the case of many elements were being discussed, solar observations were beginning to bring before us a perfect flood of facts apparently devoid of any law or order. In I866 I threw an image of the sun on the slit of a spectroscope (Fig. I), in order to observe the spectra of its different parts, and in this way the spectra of sun-spots and eventually of prominences were observed.

In the first method of work adopted in the laboratory the spectroscope was directed to the light source, so that the spectrum was built up of the light coming from all parts of it without discrimination (Fig. 2).

In I869 I introduced into laboratory work the method adopted in the case of the sun in the observatory; that is, an image of each light source experimented on was thrown on to the slit by a lens (Fig. 3), so that the spectrum of each part of it could be observed, and some of the results obtained by the new method were the following:

The spectral lines obtained by using such a light source as the electric arc or spark were of different lengths; some only appeared in the spectrum of the centre of the light source, others extended far into the outer envelopes. This effect was best studied by throwing the image of a horizontal arc or spark on a vertical slit. The lengths of the lines photographed in the electric arc of many metallic elements were tabulated and published in 1873 and 1874 (Figs. 4 and 5 ).

Here then was the first glimpse of the idea that the complete spectrum of a chemical element obtained at the highest temperature might arise from the summation of two or more different line spectra produced at different degrees of temperature, and therefore bringing us in presence of two or more molecular complexities; that is, different molecules broken up at different temperatures. So soon as experiments in the laboratory had given a definite result with regard to the spectrum of a metal in this way, I proceeded to study the sun with a view of determining how that metal behaved in the sun.

This involved, first, photographs of the solar spectrum with its dark lines, photographic comparisons of these dark lines with the bright lines constituting the spectra of the metallic elements. This enabled us to compare the total light given by each light source with the light received from all parts of the sun indiscriminately.

Next the spectra of different parts of the sun-chromosphere and prominences and spots-were compared with different parts of the light source, the core of the arc, and the centre of the spark, and the outer regions of both.

It will be seen that the inquiry now had a very broad base, and it could be immediately tested in many ways at every stage. 
Wonderful anomalies were at once detected, lines known to belong to the same chemical element behaved differently in several ways. Some were limited to spots, others to prominences, and in solar storms different iron lines indicated different velocities. In the spectrum of the hottest part of the sun oper to our inquiries, the region namely immediately overlying the photosphere which I named the chromosphere the anomalies became legion; suffice to say that in the hottest part of the sun we could get at, the spectrum of iron then represented in Kirchhoff's map by 460 lines in the ordinary solar spectrum was reduced to three lines. temperatures than those previously employed were doing for chemistry what previous similar inquiries had done namely, indicating the existence of finer constituents in matter supposed at each point of time to be elementary.

This was the first glimpse of dissociation in relation to the production of changes in the line spectrum.

By the year 1872 the work of Rutherfurd and Secchi on stellar spectra enabled the base of the inquiry to include the stars as well as the sun. In some of the stars the existence of hydrogen, magnesium and carbon were beyond question. The point that first struck me was that in white stars like a Lyræ and Sirius, with continuous

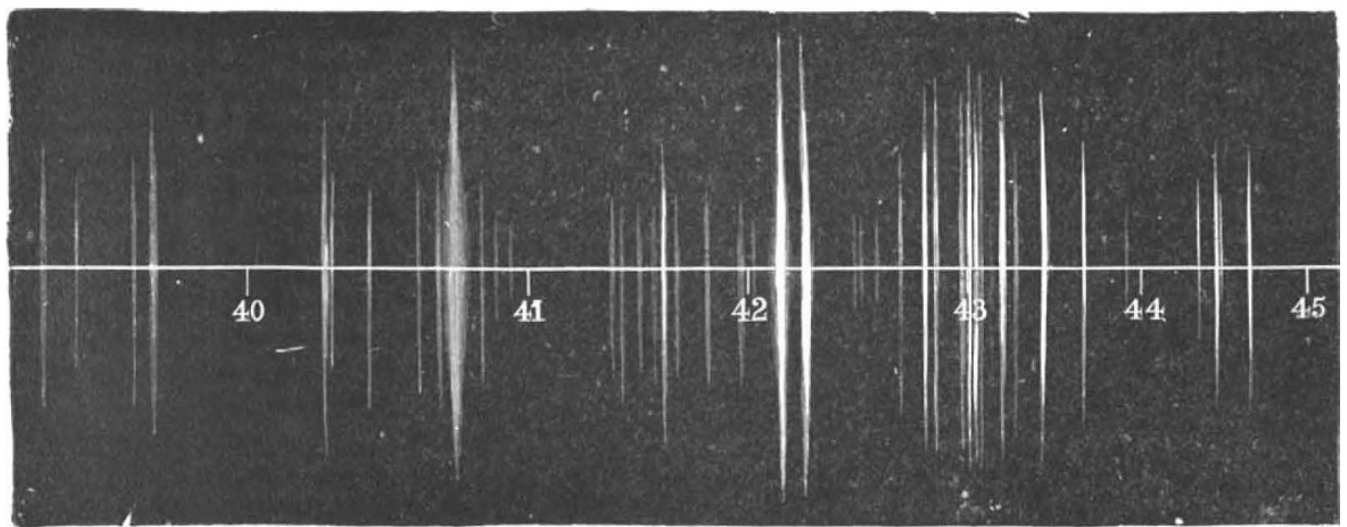

FIG. 4. - The long and short lines. Copy of a photograph taken with a vertical slit when compounds of strontium and calcium were volatilised between horizontal carbon poles.

It was no longer a question merely of settling the difficulties raised by the observations of Plücker and Hittorf.

Many observations and cross references of this kind during the next few years convinced me that the view that each chemical element had only one line spectrum

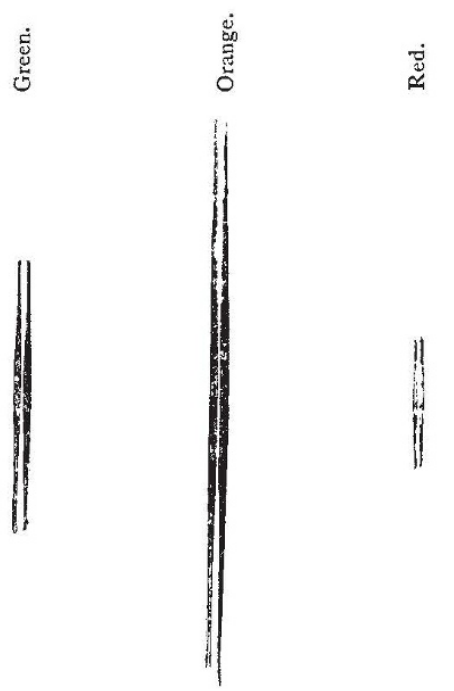

FIG. 5.-The longs and shorts of sodium taken under the same conditions, showing that the orange line extends furthest from the poles.

was erroneous, and that the results obtained suggested that the various terrestrial and solar phenomena were produced by a series of simplifications brought about by each higher temperature employed. That is, that the new instrument, the spectroscope, showed that higher spectra extending far into the violet-stars therefore hotter than their fellows of a yellow or red colour-we had to do with hydrogen almost alone.

It was in 1873 that I first called the attention of the Royal Society to the very remarkable facts which had even then been brought together regarding the possible actions of heat in the sun and stars. Referring more especially to the classification of stars by Rutherfurd, I wrote as follows : ${ }^{1}$

"I have asked myself whether all the above facts cannot be grouped together in a working hypothesis which

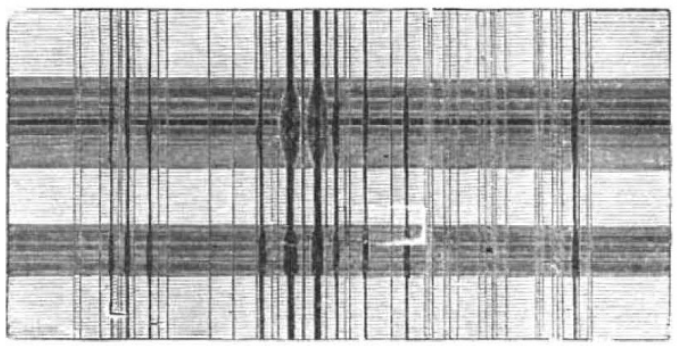

FIG. 6.-Spectrum of a sun-spot as compared with the general spectrum, showing that certain metallic lines (sodium an calcium in this instance) are widened. The darker portion represents the spectrum of the spot.

assumes that in the reversing layers of the sun and stars various degrees of 'celestial dissociation' are at work, which dissociation prevents the coming together of the atoms which, at the temperature of the earth and at all artificial temperatures yet attained here, compose the metals, the metalloids, and compounds."

Subsequently in a private letter to M. Dumas, who took the keenest interest in my solar work, I wrote, "Il semble que plus une étoile est chaude plus son spectre est simple."

\footnotetext{
1 Phil. Trans., vol. clxiv. part 2, p. 49J.
} 
I also pointed out the close relation of hydirogen to calcium, magnesium, and other metals (it was on this

Academy of Sciences was thus concluded by $M$. Dumas:

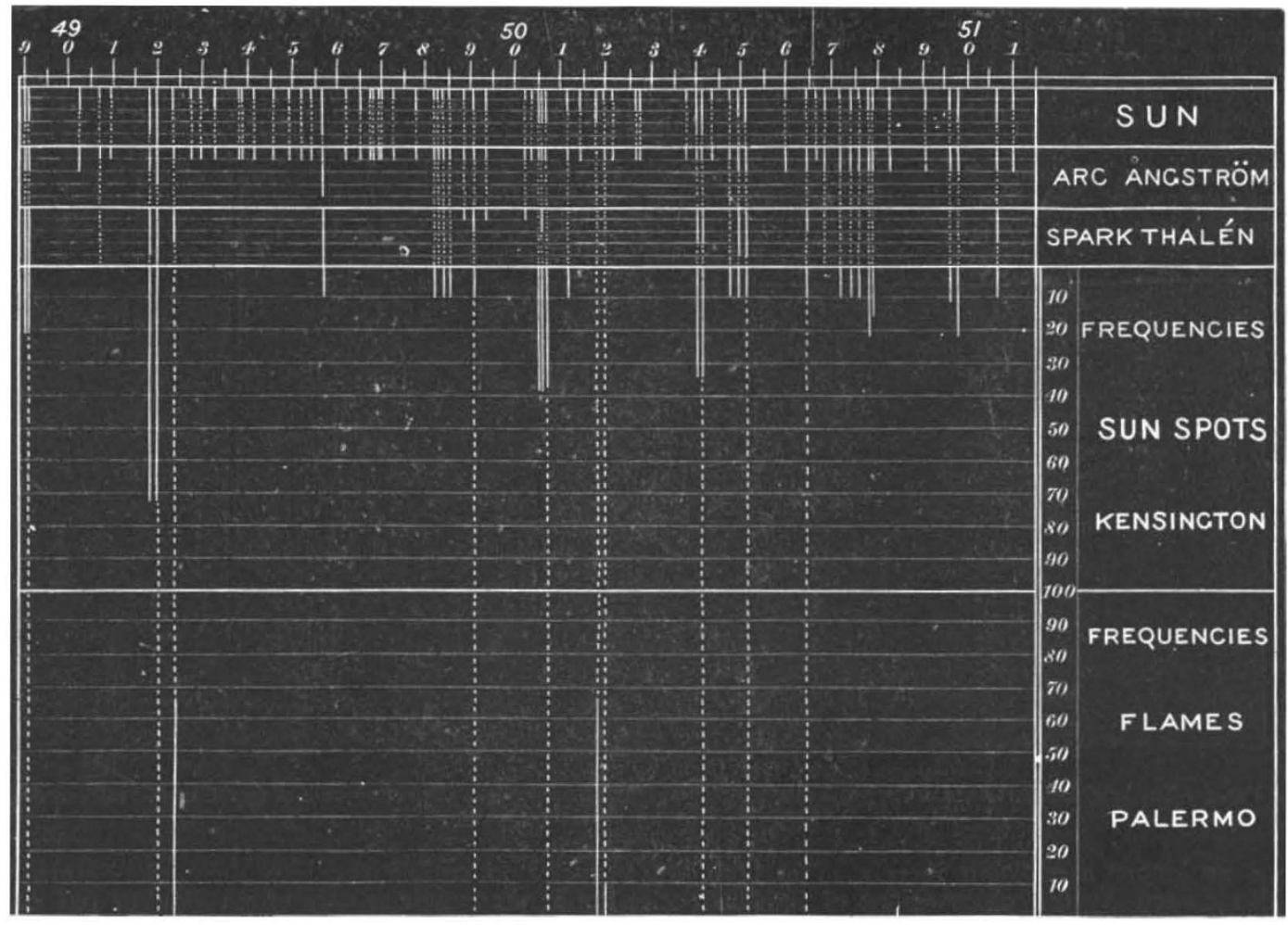

FIG 7.--Iron spot lines at Kensington confronted with iron prominence lines at Palermo.

ground that I had named the substance which gave $\mathrm{D}^{3}$, “En résumé, quand je soutenais devant l'Académie which always varied with hydrogen, helium), and the que les éléments de Lavoisier devaient être considérés,

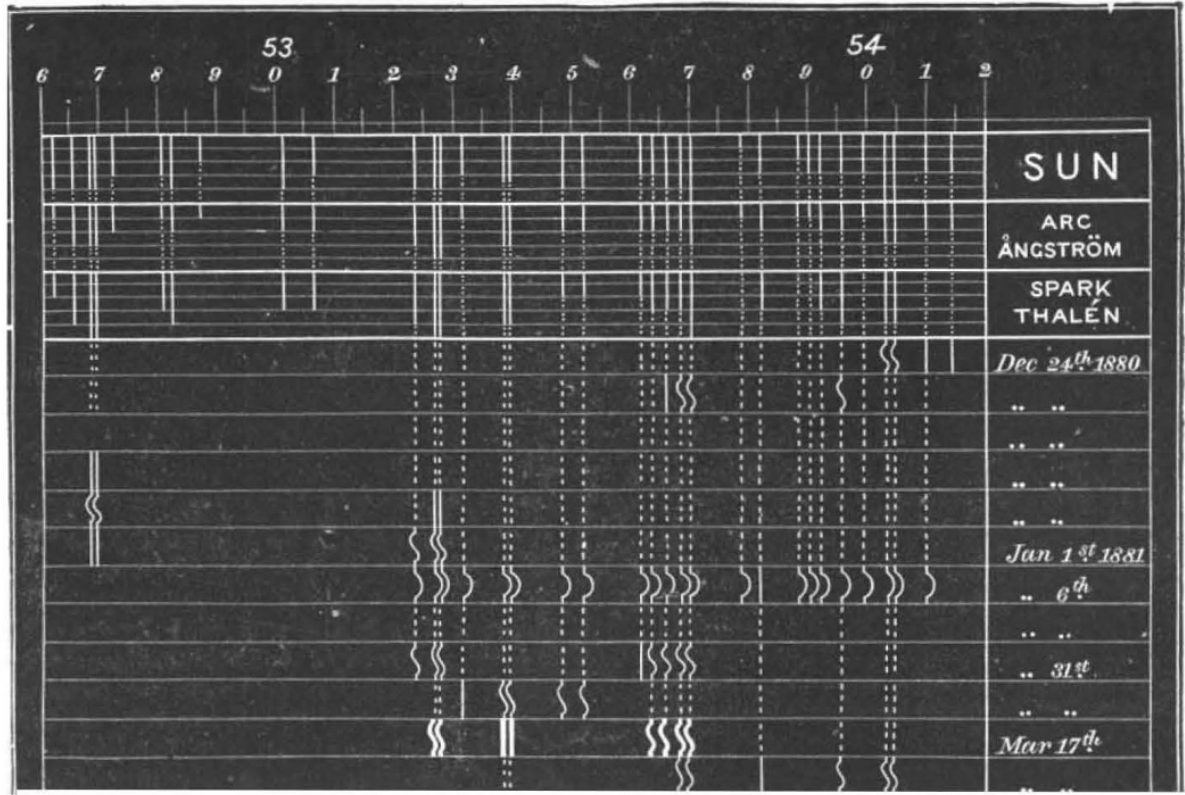

FIf. 8.-Different rates of motion registered by different iron lines.

absence of all other terrestrial gases from the solar | ainsi qu'il avait établi lui-même, non comme les éléments spectrum. An interesting discussion at the Paris absolus de l'univers, mais comme les éléments relatifs de NO. I 536 , VOL. 59] 
l'expérience humaine; quand je professais, il y a longtemps, que l'hydrogine était plus près des métaux que de toute autre classe de corps; j'émettais des opinions que les découvertes actuelles viennent confirmer et que je n'ai point à modifier aujourd'hui." 1

One of the replies to my working hypothesis was that the various chemical elements probably existed in different proportions in the different stars, and that it so happened that in Vega and Sirius one of them, hydrogen, existed practically alone.

In I 878 I went furtber, and showed that thousands of solar phenomena which had been carefully recorded during the previous years could only be explained by assuming that the changes in the various intensities of lines in the line spectrum itself indicated successive dissociations. I pictured the effect of furnaces of different temperatures, and I wrote as follows: ${ }^{2}$

"It is abundantly clear that if the so-called elements, or, more properly speaking, their finest atoms-those that give us line spectra-are really compounds, the compounds must have been formed at a very high temperature. It is easy to imagine that there may be no superior limit to temperature, and therefore no superior limit beyond which such combinations are possible, because the atoms which have the power of combining together at these transcendental stages of heat do not exist as such, or rather they exist combined with other atoms, like or unlike, at all lower temperatures. Hence association will be a combination of more complex molecules as temperature is reduced, and of dissociation, therefore, with increased temperature, there may be no end."

In 1878 I went back to the study of the changes in the line spectra in relation to the changes observed when known compounds were dissociated, and after discussing certain objections I submitted the conclusion that the known facts with regard to the changes in line spectra " are easily grouped together, and a perfect continuity of phenomena established on the hypothesis of successive dissociations analogous to those observed in the cases of undoubted compounds." 3

It is thus seen that the conclusions to which my spectroscopic work up to the year 1880 had led me, tended in exactly the same direction as that indicated by more purely chemical inquiries thus referred to by Berthelot in that year:-

"L'étude approfondie des propriétés physiques et chimiques des masses élémentaires, qui constituent nos corps simples actuels, tend chaques jour d'avantage à les assimiler, non à des atomes indivisibles, homogènes et susceptibles d'eprouver seulement des mouvements d'ensemble, ... . il est difficile d'imaginer un mot et une notion plus contraires à l'observation; mais à des édifices fort complexes, doués d'une architecture spécifique et animés des mouvements intestins très variés." 4

NORMAN LOCKYER.

DRIFT-BOTTLES AND SURFACE CURRENTS. $T$ HE rather anomalous results arrived at by some or bottle method of ascertaining the surface movements of the waters of the sea, make the discussion of a large number of these observations of special value at the present time. Such is to be found in Dr. Schott's able and elaborate paper on the "Flaschenposten" in the possession of the Deutsche Seewarte, published a short time ago in the Archiv.

After an historical introduction, in which it appears that the earliest recorded current observation of this kind is

1 "Chemistry of the Sun," p. 205.

2 Proc. Roy. Soc., vol. xxvili. p. I69. See also "Chemistry of the Sun," chap. xviii.

3 Roy. Soc. Proc., vol. xxviii. p. 179 .

4 Comptes rendus, r880, vol. xc. p. I5I2.

NO. I 536 , VOL. 59] about a century old, Dr. Schott describes the material at his disposal, which consisted of about 600 records found up to the end of the year 1896 . One important point here brought out is that no consistent difference can be observed in either direction or rate of drift between empty floats and floats loaded so as to ensure complete immersion.

In arranging the records obtained from each of the great oceans, the first place is, of course, given to the North Atlantic, which includes no less than 452 , or 70 per cent. of the whole. The North Atlantic reçords are subdivided into six sections-those from floats set adrift in the North Sea and the English Channel; in the west wind region north of $30^{\circ} \mathrm{N}$. lat.; in the north-east trade wind region; those in the south-east trade wind region which were recovered beyond its northern limit; those in the region of south-west monsoons, and in the Mediterranean. The charts appended to the paper, of which we reproduce a specimen, contain only a selected number of the drift-tracks dealt with; full details are given in tabular form. In the cise of the other oceans, the whole of the observations are represented; the South Atlantic and the Pacific are each treated as a whole, while the Indian Ocean is divided into the monsoon region, the south-east trade belt, and the "brave west winds."

Summing up in a final paragraph, Dr. Schott concludes that on the whole the method of drift-bottles yields valuable information both as to the direction and speed of surface currents. From this, however, the monsoon regions are expressly excepted : the number of bottles found within the period of one monsoon is necessarily small, and the few found give unsatisfactory results. As specially favourable instances, Dr. Schott quotes his results in the Bay of Biscay, disproving the existence of Rennell's current (no reference is made, by the way, to the work of Hautreux); in the West Indies, where the concentration of immense quantities of surface-water from the coast of Portugal and from the South Atlantic is clearly shown ; in the west wind drift of the southern hemisphere, and in the splitting of the southern equatorial current off the east coast of Madagascar. In this connection special stress is rightly laid on the record of two bottles, one loaded with sand and the other not, thrown overboard from the s.s. Paranagua in $13^{\circ} 49^{\circ}$ N. lat. and $25^{\circ} 34^{\prime} \mathrm{W}$. long., and picked up together on the island of Santiago (Cape Verd Island) after a journey of I 31 miles in twenty-one days, the direction being north-east by east with a weak current (whose existence was shown by independent observations recorded in ships' logs), and asainst the wind blowing at the time. In estimating the speed of current, the float method is found to be much less valuable, inasmuch as we can rarely be certain that the float is picked up immediateiy after it has reached the spot where it is found. Reasonably accurate estimates can only be looked for where a number of floats gives approximately the same result.

The justness of Dr. Schott's conclusions, so far as they go, seems to admit of little doubt, but we could have wished that his final statement of them, which will probably be much more widely read than the detailed discussion in the body of the memoir, had been expressed in a more guarded manner, and that to it he had added a note of warning, pointing out not only the extremely limited nature of the information afforded by the method, but the great risk of misinterpreting its results. Taking first the question of direction of surface currents : on the whole, the surface currents in perfectly open sea, clear of all land influences, follow the direction of the wind, and the float or bottle naturally takes the course common to both. Near land, the direction of the surface current is determined by three factors : first, and most important, the form of the coast line ; second, the prevailing wind; and third, a gravity factor, due to 